\title{
Intimidade e Extimidade Virtual na Conjugalidade Contemporânea
}

\author{
Carolina Mendes Campos* \\ Terezinha Féres-Carneiro \\ Andrea Seixas Magalhães \\ Pontifícia Universidade Católica do Rio de Janeiro, Rio de Janeiro, RJ, Brasil
}

\begin{abstract}
RESUMO
Antes do boom da internet, a intimidade mantinha uma forte vinculação com a ideia de privacidade. Contudo, é notória a transformação da intimidade hoje, justamente, no que concerne à sua ligação com o espaço virtual. A internet se tornou um palco de exibição, no qual muitas informações são compartilhadas, alcançando uma visibilidade pública nunca antes imaginada. Neste trabalho, pretende-se investigar, a partir de uma revisão teórica, as possíveis repercussões que esse novo fenômeno observado na internet está produzindo na vivência da conjugalidade contemporânea, uma vez que os olhares parecem estar, cada vez mais, magnetizados pelas relações com os inúmeros outros virtuais. Para tal, será apresentada a atual perspectiva da intimidade vazada na exterioridade pública das telas, aqui denominada de extimidade virtual, refletindo sobre os seus novos desafios.
\end{abstract}

Palavras-chave: intimidade; extimidade virtual; conjugalidade.

\section{ABSTRACT \\ Intimacy and Virtual Extimacy in Contemporary Conjugality}

Before the internet boom, intimacy was highly connected to the idea of privacy. However, it is notorious the transformation of intimacy today, especially in what concerns its relationship to the virtual space. The internet became a stage for exhibition, in which lots of information is shared, achieving a public visibility never imagined before. In this work, we aim to investigate, throw a theorical review, the possible repercussions that this new phenomenon observed in the internet is producing in the experience of contemporary conjugality once the eyes seem to be increasingly magnetized by the numerous virtual others. In order, to reach this goal, we will present the perspective of casting intimacy into public externality - coined as virtual extimacy - reflecting on its new challenges.

Keywords: intimacy; virtual extimacy; conjugality.

Desde o advento da modernização e da industrialização das sociedades ocidentais, que produziu a dicotomia das esferas do público e do privado, havia uma clara fronteira que estabelecia a exploração da intimidade dentro dos limites da casa, da família e do casamento. Deste modo, a intimidade esteve, durante muito tempo, vinculada à ideia de privacidade (Corbin, 2009; D'Incao, 2013; Ferry, 2008; Jablonski, 1998; Lasch, 1991; Perrot, 2009; Prost, 2012; Sennett, 1993; Sibilia, 2008). Contudo, hoje, identificamos significativas transformações na intimidade, justamente, no que concerne à sua vinculação com o privado. A in- ternet e suas ferramentas de comunicação, conhecidas como redes sociais, têm produzido uma nova forma de lidar com a intimidade, já que nestes espaços virtuais, muitas informações são compartilhadas, alcançando uma visibilidade pública nunca antes imaginada.

Por considerarmos que estamos diante de um fenômeno atual, que comporta especificidades próprias, optamos por denominar essa nova perspectiva da intimidade na internet de extimidade virtual. $\mathrm{O}$ termo extimidade é um neologismo que foi, primeiramente, explorado por Jacques Lacan, em seminários como "A Ética da Psicanálise" e "De um outro ao outro" (La- 
can, 1988, 2008; Miller, 2011). Posteriormente, foi retomado pelo também psicanalista francês Tisseron (2008). Entretanto, ressaltamos que a utilização desse termo, no presente trabalho, não está associada às ideias dos referidos autores. Outras pesquisas (Bauman, 2012; Sibilia, 2008), que também versam sobre a intimidade na rede, fazem referência ao termo, mas, pretendemos, aqui, utilizá-lo com uma definição central e própria, a fim de marcar uma diferenciação entre a intimidade vivida no real e essa nova perspectiva observada hoje na rede, conforme indicaremos mais adiante.

Pretendemos investigar as possíveis repercussões que esse fenômeno de nosso tempo está produzindo na vivência da conjugalidade contemporânea, uma vez que os olhares parecem estar cada vez mais desviados para as relações éxtimas e magnetizados pela enxurrada de informações de inúmeros outros virtuais.

\section{INTIMIDADE, PRIVACIDADE E CONJUGALIDADE: A DIFERENCIAÇÃO ENTRE $O$ PÚBLICO E O PRIVADO}

Frequentemente, encontra-se a associação entre as ideias de intimidade e de privacidade. Tal associação se tornou corrente, a nosso ver, devido ao fato de existir um longo processo histórico relativo ao advento da modernização das sociedades ocidentais, que produziu a clássica dicotomia entre as esferas do público e do privado. Portanto, havia de um lado a rua, espaço público do trabalho, marcado pela característica do anonimato e da instrumentalidade. Do outro, havia a casa, espaço privado da família, fortemente vinculado à ideia de pessoalidade e de intimidade (Sennett, 1993; Vaistman, 1994). Neste sentido, a intimidade remetia, até então, ao que não era compartilhado com a maioria, isto é, ao que deveria ser preservado do olho público. Essa dicotomia social sustentou por muito tempo uma clara divisão, que favorecia a exploração da intimidade dentro dos limites da casa, da família e do casamento, circunscrevendo, assim, um espaço delimitado por paredes que a protegiam.

A noção de intimidade nem sempre teve uma representação específica na vida das famílias e dos casais. A vida social e privada, até o século XIX, não tinha uma divisão clara, prevalecendo o referencial da coletividade. As pessoas nunca estavam sós, pois viviam em espaços sem divisões, nos quais dificilmente conseguiam buscar o isolamento. A própria organiza- ção das casas não contava, necessariamente, com cômodos independentes, o que dificultava um relacionamento mais próximo entre as pessoas (Del Priore, 2011; Ferry, 2008; Perrot, 2011). Esse contexto que não favorecia a intimidade só foi efetivamente modificado a partir do movimento de interiorização das famílias, decorrente do processo de modernização e industrialização da sociedade (Corbin, 2009; D'Incao, 2013; Jablonski, 1998; Perrot, 2009; Prost, 2012; Sibilia, 2008).

A função da família anterior à modernização estava fortemente atrelada à noção de trabalho, já que ela deveria promover e manter a maior parte dos meios necessários à sobrevivência de seus membros, tais como alimentação, vestuário, educação, saúde, entre outros. O processo de modernização e industrialização deslocou o trabalho para as atividades realizadas pelos homens no espaço público, vinculando-o mais diretamente à remuneração. Como consequência deste deslocamento a família sofreu uma expressiva perda de função, visto que, como pontua Jablonski (1998), várias tarefas a ela pertencentes foram entregues a instâncias e agências sociais. Para o autor, a modernidade veio relativizar a função historicamente básica da família que consistia em garantir a sobrevivência de seus membros.

Além disso, outra importante mudança, derivada da interação entre família e modernidade, diz respeito ao seu encurtamento, já que, em muitos casos, houve uma significativa diminuição no número de filhos, além de uma quebra no antigo costume de agregar primos, afilhados e serviçais em torno do núcleo central dos pais e dos filhos. Todas essas perdas de funções e de membros ocorridas nas famílias produziram, gradativamente, o seu isolamento e, consequentemente, uma retração da sociabilidade. Ilhada em grupos solitários de pais e filhos, a família moderna, ou, como sugere Jablonski (1998), a "fam-ilha", passou a reforçar os muros da privacidade, fato este, bastante contrastante em relação à sua anterior configuração, profundamente atrelada ao coletivo. Em contrapartida, coube à família uma nova e nobre função: a de refúgio da afetividade (Lasch, 1991). Assim, o âmbito privado passou a representar o espaço fecundo para a exploração da intimidade, em contraste com o aspecto instrumental e frio, característico da esfera pública do trabalho.

Sennett (1993) aponta para o gradativo declínio da vida pública proveniente dos traumas que o capitalis- 
mo industrial produziu na sociedade burguesa do século XIX. A competitividade vivida na esfera pública do trabalho, com a cobrança de se tornar alguém nas ruas, de lutar por um espaço em meio aos estranhos, acabou por suscitar um silencioso isolamento. Os burgueses gradativamente deixaram de tentar controlar este clima hostil da ordem pública e passaram a preferir se proteger dele. Desta forma, a família foi se transformando em um espaço idealizado, em uma espécie de escudo protetor, no qual as pessoas se refugiavam. Além disso, o autor afirma que o mito de que os males da sociedade são derivados da impessoalidade, da alienação e da frieza acabaram por desembocar na ideologia da intimidade, na qual o vínculo afetivo, próximo e pessoal passou a ser considerado como um bem moral.

Essa clássica dicotomia moderna entre o público e o privado no que concerne à realidade brasileira foi foco de análise de DaMatta (1997). Para o autor, existem claras mudanças em nossas atitudes quando estamos em casa ou na rua, que variam desde gestos, assuntos, papéis sociais, até mesmo ao modo como nos vestimos. Em casa, somos "supercidadãos", pois podemos exigir atenção, querer um lugar determinado e permanente na família, requerer nosso espaço próprio, ou seja, em casa, não somos indivíduos, somos pessoas. Já na rua, somos "subcidadãos", já que nela passamos por indivíduos anônimos, que não possuem nem paz nem voz, estamos diluídos na massa, no impessoal. DaMatta (1997), ainda ressalta que "de casa vêm também casamento, casadouro e casal, expressões que denotam um ato relacional, plenamente coerente com o espaço da morada e da residência" (p.50). Assim, tal cisão moderna consolidou a privatização da intimidade e revalorou as relações pessoalizadas existentes entre as quatro paredes da casa.

Além disso, a dicotomia entre o público e o privado ocorrida com a modernização pode ser considerada também pela perspectiva de gênero, na medida em que ela instaurou profundas diferenciações entre homens e mulheres. Todas as modificações derivadas do processo de modernização no âmbito privado produziram um novo modelo de família, denominado de família conjugal moderna (Jablonski, 1998; Singly, 2007; Vaistman, 1994) ou de família burguesa nuclear (Ariès, 1981; Badinter, 1985). Ambas as designações são utilizadas para caracterizar este novo modelo pautado na livre escolha e no amor. Porém, apesar dos ideais românticos e igualitários presentes nesse novo modelo, ele pemaneceu impregnado de valores hierárquicos e patriarcais, que sustentavam a subordinação da mulher frente ao homem. Como ressalta Vaitsman (1994), a rua era a esfera do masculino, dos trabalhadores e provedores, detentores do status social e a casa o espaço do feminino, posto que as mulheres foram devidamente excluídas dos contornos públicos, ficando encarregadas do ofício do lar, considerado, até então, como invisível, sem valor e improdutivo. Em contrapartida, a criação do lar como lugar de proteção e afeto, a modificação nas relações entre pais e filhos e a chamada invenção da maternidade (Badinter, 1985) colaboraram para a construção de uma aura feminina nas questões pertinentes à intimidade. Ainda segundo Vaistman (1994), a mulher passou a representar "a própria encarnação de tudo aquilo que a vida privada e familiar passou a significar no plano do imaginário social" (p. 31).

Somente a partir da segunda metade do século XX, as mulheres passaram a desafiar de forma mais notória a ordem estabelecida, com o ingresso consistente no mercado de trabalho. Essa atitude desestabilizou a dicotomia entre as duas esferas sociais, exigindo que os valores igualitários pudessem de fato sair do plano ideal e, assim, ganhassem contornos mais palpáveis. $\mathrm{O}$ movimento de inserção feminina na arena pública afetou ainda mais as relações da família e do casamento, uma vez que elas passaram a se dividir entre esses dois âmbitos e, consequentemente, passaram, também, a exigir uma maior participação masculina nas tarefas da vida íntima, do lar e dos filhos.

No recente contexto no qual homens e mulheres flexibilizaram as fronteiras da dicotomia social e se tornaram mais iguais, as exigências emocionais, o ideal de amor e a ênfase no sentimento de intimidade se tornaram ainda fortes. Giddens (1993) também destaca a importância que as reivindicações femininas tiveram para a criação de uma nova ordem nas relações amorosas, que priorizasse a igualdade na doação e no recebimento emocional para ambos os sexos. Para o autor, os princípios democráticos e os valores igualitários foram profundamente incorporados à dinâmica cotidiana das sociedades ocidentais, principalmente, a partir da segunda metade do século XX, a tal ponto que viabilizaram uma profunda transformação da intimidade. Isso se fez notar na maneira pela qual os relacionamentos afetivo-sexuais passaram a ser constituídos. Giddens (1993) salienta a emergência do relacionamento puro, que seria fruto das reivindicações feministas, como 
modelo significativo destes novos valores, que se alicerça em bases democráticas. Tal relacionamento, ao contrário do casamento tradicional, fortemente pautado pelas regras sociais, aproximou as noções de amor e sexualidade e encontrou como base a exploração da intimidade. Assim, os envolvidos em um relacionamento puro passaram a ter como objetivo principal a busca da satisfação pessoal, intensificando as expectativas a respeito de suas relações e mantendo estes vínculos apenas enquanto eles permanecessem satisfatórios para ambas as partes.

Antes destas marcantes transformações, o casal era uma das partes constituintes da família, juntamente com os filhos e os demais parentes. Contudo, hoje, o casal está no centro do que se entende por família e sua formação independe de um ato institucionalizado (Féres-Carneiro, Ziviani, \& Magalhães, 2011; Giddens, 1993; Lasch, 1991). Giddens (1993) ainda ressalta que, no passado, o casamento não tinha como base a exploração da intimidade, isso era, sem dúvida, importante para uma boa relação, mas não era o fundamental. Já para os casais da atualidade a intimidade passou a assumir um lugar de centralidade e base para uma possível relação. Portanto, o que está agora em jogo na constituição das relações conjugais está muito mais ligado à qualidade dos sentimentos que unem os parceiros, do que o vínculo formal, que era uma das bases do modelo tradicional de casamento. Por um lado, isso proporcionou o advento de múltiplas novas configurações de relacionamento, mas, por outro, depois de desfeitas as sólidas amarras que sustentavam a rigidez do modelo tradicional, as questões envolvidas na construção da conjugalidade e da intimidade passaram a ser mais explícitas (Féres-Carneiro, Ziviani, \& Magalhães, 2011).

Cabe salientar que todo esse itinerário histórico que vincula a intimidade ao privado, à casa, à família e à mulher acabou por construir uma nova dimensão do que entendemos por conjugalidade. Na medida em que a família passou a ser entendida como o espaço de afeto, de amor e de cumplicidade, tais ideais elevaram o casal a um lugar de centralidade, produzindo assim a intrínseca relação entre a intimidade e a conjugalidade.

\section{EXTIMIDADE VIRTUAL: A NOVA PERSPECTIVA DA INTIMIDADE NA CONTEMPORANEIDADE}

Nesse ponto, nos propomos a pensar a respeito da nova perspectiva da intimidade na contemporaneida- de, uma vez que consideramos que o cenário atual é marcado por uma transformação desta, precisamente, no aspecto que concerne à sua vinculação com o privado. O mundo de hoje vive um excessivo apelo de visibilidade, que vem aos poucos desestabilizando as sólidas e opacas paredes da privacidade que protegiam a intimidade. Assim, a intimidade agora é chamada a se mostrar, a aparecer diante do olhar dos outros, não mais se restringindo ao plano privado da casa, da família e do casamento. Essa transformação, a nosso ver, é claramente percebida no boom da internet e de suas ferramentas de comunicação, conhecidas como redes sociais, que proliferaram por todo o mundo ao longo da primeira década do século XXI.

Tisseron (2005) aponta para as mudanças dessa fase em que vivemos, na qual todas as novas tecnologias permitiram uma releitura daquilo que antes era restrito ao âmbito privado. Para o autor, a escrita na internet permite compartilhar com milhões de desconhecidos informações que seriam relevantes, na maior parte das vezes, apenas à esfera íntima. Essa novidade de nosso tempo faz com que a noção de intimidade se modifique radicalmente, já que, antes, existiam espaços que, por tradição, estavam diretamente relacionados a ela, como a casa, o quarto e o banheiro. Já nos dias de hoje, com a internet, mais do que uma questão de espaços socialmente definidos, a intimidade, para Tisseron, remete à ideia de uma escolha pessoal, isto é, de uma intenção, que ele resume da seguinte maneira: "a intimidade é onde eu quero, quando eu quero" (Tisseron, 2005, p. 272, tradução nossa).

Tisseron (2008) ainda destaca que houve um longo caminho de preparação para as mudanças que vivemos. Primeiramente, habituamo-nos ao telefone, que nos ensinou a acharmos natural o fato de falarmos com os outros sem vê-los. A má qualidade do som ao telefone era indicativa de que estávamos realmente longe um do outro. Porém, quanto mais avançamos nas tecnologias digitais e alcançamos uma qualidade cada vez melhor para as conexões, sentimos que o distante se tornou próximo. Passamos a escutar a voz do outro de modo mais nítido e, portanto, passamos a sentir o outro como mais presente.

Outra etapa de preparação ocorreu com o desenvolvimento da fotografia. Habituamo-nos a ver nossa própria imagem não mais refletida apenas nos espelhos, mas também nas fotografias. Aceitamos, gradativamente, a fotografia como representante da nossa imagem. Hoje, da mesma forma, com o avanço tecno- 
lógico, temos uma nova característica dessa imagem, que remete à possibilidade de multiplicação e de edição. Para Tisseron (2008), as fotografias digitais são novos espelhos de pixels nos quais escolhemos, fabricamos e endireitamos a aparência que desejamos ter e mostrar.

Por fim, o autor destaca a televisão como mais uma etapa de preparação para a realidade virtual que hoje vivemos com a internet. Com a televisão habituamonos ao exercício de discernir entre realidade e ficção. Entretanto, os avanços tecnológicos permitiram a reedição de imagens antigas, que agora são recoloridas, aparentando serem atuais. O contrário também é possível e, assim, imagens do tempo presente são trabalhadas, aparentado pertencerem a outra época. Tisseron (2008), então, interroga a respeito do estatuto dessas imagens: seriam elas realidades ou ficções? Para o autor, essa nova versatilidade fluida das imagens coloca os indivíduos contemporâneos diante da liberdade de escolha, ou seja, se é verdadeiro ou falso é cada um quem decide.

No espaço virtual da internet, que vem se tornando cada vez mais a Ágora da contemporaneidade, percebemos nitidamente a naturalidade alcançada pelas etapas descritas por Tisseron (2008). Através da tela, o distante se torna próximo, ficção e realidade se entrelaçam e os antigos espelhos são substituídos por múltiplas imagens editadas de pixels. Além disso, buscamos na tela não apenas informações sobre o mundo, sobre os outros, mais ainda, buscamos a nós mesmos, deslizando nos teclados em busca de olhares que afirmem o que somos, ou, pelo menos, o que pretendemos parecer ser.

Sibilia (2008) reflete sobre essa exposição da intimidade na internet apontando para as possíveis interferências desse fenômeno nos modos de subjetivação na contemporaneidade. Para a autora, essa forte tendência à espetacularização da vida cotidiana na internet está diretamente ligada às demandas da sociedade do espetáculo, descritas por Debord (1997). Para o espetáculo, o que mede, efetivamente, o valor da realidade individual não se refere ao que a pessoa é ou tem, mas sim ao que ela aparenta ter e ser. A enfática exigência social de parecer e aparecer passa, então, a afetar nossos modos de vida, nossa forma de olhar para o mundo, as relações que estabelecemos com os outros e conosco: "se não se mostra, se não aparecer à vista de todos e os outros não o vêem, então, de pouco servirá ter seja lá o que for. Agora, o importante é parecer" (Sibilia, 2008, p. 84).

Neste sentido, as novas ferramentas, como as redes sociais da internet, acabam por ganhar um espaço gigantesco em nosso cotidiano, já que favorecem a exploração desse parecer ser, desse brincar de ser, além de permitirem uma abrangência de visibilidade nunca antes imaginada. Segundo Sibilia (2008), tais ferramentas fornecem, hoje, um convite à confissão, um espaço no qual qualquer um pode divulgar e confessar os seus segredos, produzindo, assim, novas formas de subjetivação, formas mais epidérmicas, que se desdobram em subjetividades visíveis, que querem ser curtidas, comentadas, compartilhadas e que contam com essa intimista aldeia global que é a rede para derramarem suas intimidades. Estar na internet é compartilhar do desejo de se tornar uma espécie de personagem visível, ou seja, é querer ser visto, além de ser igualmente instigante o desejo de ver o outro, bisbilhotar e consumir vidas alheias (Sibilia, 2010).

Mas, além da rede ser atualmente um espaço que fomenta novas formas de subjetivação, ela é também um novo espaço de interação. Vivemos cada vez mais conectados, com os olhos grudados na tela, e, assim, as relações virtualizadas têm ganhado uma proporção gigantesca em nosso cotidiano, a ponto de se transformarem em um dos acessos mais comuns que temos em termos de comunicação (Turkle, 2011). De fato, podemos perceber facilmente, em nosso cotidiano atual, que nossa comunicação com o outro, seja por questões profissionais, seja por questões pessoais, tende a ser, na maior parte das vezes, mais teclada do que falada. Isso indica que a rede é para nós, cada vez mais, o espaço imediato do encontro e da troca.

Matos-Silva, Abreu e Nicolaci-da-Costa (2012) destacam que difusão da internet explicitou prontamente a sua enorme capacidade de promover novas formas de relacionamento interpessoal e de conectar pessoas espalhadas ao redor do mundo. A rede abre espaço para uma nova espécie de comunitarismo, já que permite a aproximação de diferentes pessoas em torno do compartilhamento de interesses, preferências e afinidades. O desenvolvimento da Web colaborativa e a expansão das redes sociais deram um novo lugar aos usuários que deixaram de ser meros espectadores e passaram a ter uma participação mais ativa, publicando fotos, textos e vídeos. Segundo as autoras, esse papel mais ativo dos usuários na rede favoreceu ainda 
mais a formação de vínculos e a maior união entre as pessoas.

Essa capacidade da internet de conectar pessoas é de fato extremamente marcante e facilmente observável na febre do momento, o Facebook, a rede social que, segundo Bauman (2012), ajunta em todo o mundo números astronômicos de adeptos, que gastam mais de 700 bilhões de minutos por mês plugados nessa rede. O Facebook se tornou um espaço de resgate de contatos pessoais, de manutenção de relacionamentos a distância, além de ser uma janela de diálogo constantemente aberta, já que grande parte dos usuários está ligada a ela através de seus smartphones. Desta forma, os relacionamentos virtualizados, mesmo prescindindo do contato direto com os corpos, os olhares e os gestos são, ainda assim, capazes de promover trocas fortemente afetivas entre as pessoas.

Porém, apesar de considerarmos que as ferramentas da internet estimulam a divulgação de informações íntimas dos internautas, bem como favorecem a formação de laços relacionais fortes, optamos por não tratar desse novo fenômeno igualando-o à intimidade. Por percebermos especificidades próprias, preferimos denominá-lo de extimidade virtual, a fim de designarmos o que consideramos como a nova perspectiva da intimidade no espaço da rede. O que aspiramos marcar com essa denominação é, justamente, o surgimento de uma nova relação entre o que é informação e relação íntima e sua exposição e vivência, agora não mais restrita e protegida pelo âmbito privado, mas também requerida e estampada na vitrine do espaço público da internet. Desejamos, assim, apontar para uma diferenciação entre a intimidade vivida no real e essa nova perspectiva observada no virtual, uma vez que os muros da privacidade que protegiam a primeira parecem, hoje, desabar em prol da almejada visibilidade alcançada nas telas dos computadores. Deste modo, entendemos por extimidade virtual esse marcante desejo de compartilhar informações, de expor a si mesmo através de fotos, frases, testemunhos, relatos confessionais, bem como dessa nova possibilidade de estabelecer contatos íntimos no espaço êxtimo da rede.

\section{CONJUGALIDADE CONTEMPORÂNEA: OS DESAFIOS DA INTIMIDADE E AS POSSÍVEIS REPERCUSSÕES DA EXTIMIDADE VIRTUAL}

Uma propaganda exibida na TV de uma operadora de celular mostra uma cena em um restaurante, na qual um casal está sentado à mesa, ambos com os olhos fixos em seus celulares. O locutor diante deles apresenta uma oferta de um novo pacote que garante acesso à internet o tempo todo e em qualquer lugar. $\mathrm{O}$ rapaz, sem retirar os olhos da tela, estende a mão e começa a acariciar um pedaço de pão, pensando que é a mão da moça. O locutor, então, intervém, retira sua mão do pedaço de pão e une as mãos do casal, exclamando aos telespectadores: com todos esses serviços e vantagens você não vai ficar assim como eles. Nós queremos que você continue aproveitando o que há de melhor na vida real!

Essa cena serve de pista para pensarmos a respeito das possíveis repercussões que a extimidade virtual pode estar produzindo para a conjugalidade hoje. A tela, independentemente do tamanho, parece ter se transformado em um campo que magnetiza os olhares e que os desvia do outro concreto, para os inúmeros outros virtuais. Essas transformações têm gerado, a nosso ver, novos impasses para os casais. Se a exploração da intimidade na conjugalidade, por si só, já representa um enorme desafio para os parceiros, agora, então, frente às novas demandas da extimidade virtual, tal desafio parece se anunciar como ainda maior.

O desafio da intimidade na conjugalidade parece começar com a própria diferença observada entre os gêneros, ou seja, homens e mulheres parecem ter diferentes compreensões a respeito do que vem a ser intimidade. Goldenberg (2010) discute essas diferentes perspectivas de homens e mulheres, salientando que sua pesquisa sobre o tema revelou um verdadeiro abismo entre eles no que diz respeito ao valor e ao significado da intimidade. Para as mulheres, a intimidade está vinculada a uma forte carga emocional, que se expressa em uma maneira especial de comunicação. Por esse motivo, elas se queixam de não conseguirem estabelecer este tipo de vínculo com seus parceiros. Reclamam de falta de intimidade, já que os homens, na maioria das vezes, se portam de forma racional, prática e objetiva e, logo, são vistos por elas como frios e distantes. A queixa principal deles diz respeito à falta de compreensão por parte das mulheres, na medida em que elas se mostram muitas vezes insatisfeitas, mesmo diante dos esforços masculinos de corresponder e agradar.

A vinculação entre intimidade e conjugalidade foi amplamente absorvida como modelo ideal de relação, por se pautar em boas intenções, que valorizam a tro- 
ca, a cumplicidade e o amor em detrimento do modelo anterior de casamento, no qual tais questões eram desconsideradas. As transformações do casamento ocorridas no século XX colocaram, então, a exploração da intimidade como o fundamento para uma boa relação e como o grande termômetro para se medir a qualidade dos vínculos estabelecidos. Sabemos que tal vinculação embalada em boas intenções é, por um lado, muito importante para tecermos sentidos, para doarmos certa ordem às nossas vidas, porém, por outro lado, essa vinculação se apresenta como uma árdua tarefa, já que, afinal, desejamos a intimidade, mas nem sempre somos capazes de construí-la ou de suportá-la. Isto porque, na intimidade conjugal, se faz necessária, a nosso ver, a paradoxal construção de certo equilíbrio entre a abertura para o outro e o limite necessário para se estabelecer uma boa relação. Nesta perspectiva, Giddens (1993) ressalta a importância da clara definição dos limites de um relacionamento para a manutenção de uma intimidade satisfatória. Para ele, intimidade não significa deixar ser absorvido pelo outro, mas, ao contrário, a possibilidade de poder reconhecer as características do parceiro, bem como a de colocar as suas próprias características, disponíveis para a relação.

Féres-Carneiro (1998) colabora para essa discussão através do que considera como a fascinante dificuldade de ser casal. O que está em jogo no ato de constituição de uma identidade de casal é, justamente, o difícil convívio das individualidades com a conjugalidade. Se isso já se desdobra em um enorme desafio, a autora adverte que, hoje, tal problemática é ainda maior devido ao intenso apelo aos ideais individualistas de nossa sociedade, que lançam os casais diante de forças contraditórias, que exigem a preservação das individualidades, ao mesmo tempo em que se deseja conjugar uma vida a dois.

Sabemos que, diante de tais apelos individualistas, muitos casais prezam por espaços privados dentro da própria casa como escritórios próprios, armários próprios, computadores próprios e, até mesmo, em alguns casos, banheiros próprios. É como se as pessoas, hoje, necessitassem estabelecer nichos privados dentro do próprio espaço privado. Da mesma maneira, essa necessidade se estende ao tempo. Existe o tempo do casal, mas também é desejável que exista o tempo próprio, no qual cada um possa se dedicar aos seus hobbies, encontrar seus amigos pessoais (Heilborn, 2004).
Féres-Carneiro (2001) destaca que em suas pesquisas com casais, tanto os homens quanto as mulheres, defendem a preservação de espaços para os segredos em suas relações. Para eles, os segredos são importantes para a manutenção da individualidade e da privacidade, com a ressalva de que devem ser preservados desde que não interfiram diretamente na relação. Todas essas necessidades de individualidade dentro da conjugalidade se chocam com as demandas da intimidade, já que por um lado desejamos estar-com, mas por outro, não queremos abrir mão de nosso espaço individual. Tal armadilha lança a perguntar: como é possível ser casal e dispor de uma abertura suficiente para que a intimidade possa se desenvolver se não se pode abrir mão das individualidades?

Além da individualidade, destacamos também o ideal romântico que elevou o amor à condição de valor e base para a conjugalidade contemporânea como outro desafio na construção e na manutenção da intimidade. Os estudos de Jablonski $(2003$; 2011) referentes às expectativas diante do casamento revelam que o amor, frequentemente, aparece como máxima capaz de fazer uma relação durar. O autor salienta que nossa cultura dá extrema relevância ao amor-paixão, criando uma atmosfera mágica e sedutora ao seu redor. Uma das expectativas mais comuns é a de que um dia encontraremos nossa cara-metade, com quem será possível viver uma relação complementar, satisfatória e feliz. Nesse sentido, ressalta o autor, que nossa sociedade sustenta uma visão hollywoodiana da afetividade e toma, então, o amor-paixão e o casamento como sinônimos. Desta forma, os casais de hoje, filhos de uma cultura que vê na paixão uma espécie de almejado salvo-conduto universal, acabam por se frustrarem, na medida em que carregam expectativas muito difíceis de serem alcançadas.

Além dos desafios da intimidade, destacamos também as possíveis repercussões que a extimidade virtual tem produzido na vivência da conjugalidade de hoje. Uma recente pesquisa aponta para o fato de que as redes sociais têm sido cada vez mais citadas nos pedidos de divórcio e de separação em muitos países (Royo, 2012). Esse dado pode ser confirmado em nossas escutas clínicas, onde muitas vezes encontramos relatos sobre os conflitos gerados na rede. Comentários lidos podem se tornar suspeitos, fotos postadas podem se tornar flagrantes. Isso porque, como apontamos, a internet permite uma evasão de conteúdos partilhados que antes da sua existência não eram passíveis de 
acesso. Como lidar com essa enxurrada de informações? Como interpretá-las?

O Facebook é certamente um exemplo claro das manifestações da extimidade virtual contemporânea. A própria dinâmica do site estimula a exposição de si, uma vez que na página inicial são colocadas perguntas, tais como: "No que você está pensando?; Como está se sentindo?; Como vai?; O que está acontecendo?". Essas perguntas servem de motivação para que os participantes postem ali conteúdos relacionados ao seu perfil, fotos de viagens, locais que frequenta, livros que lê, além de ser, também, um espaço de diálogo no qual, dependendo das configurações de privacidade escolhidas, é possível compartilhar conteúdos e conversar, inclusive com desconhecidos.

Contudo, cabe ressaltar outra especificidade desse mundo íntimo virtual, do qual o Facebook é efetivamente um dos representantes principais. Trata-se do fato que, por um lado, tem-se uma teia interconectada, visível, e acessível em um clique. Porém, por outro, essa atmosfera aberta ainda conserva certo ar privativo, já que é mediada por senhas pessoais que interditam o acesso. Desta forma, o mundo virtual é formado por duas facetas: uma pública e outra privada, e, por esse motivo, nem todos os conteúdos e conversas podem ser do acesso de todos.

Essa complexa teia virtual que interpenetra o público e o privado é, então, realmente propícia a produzir desconfianças e ciúmes como aponta uma pesquisa canadense (Muise, Christofides, \& Desmarais, 2009). Os autores esclarecem que o Facebook representa um fenômeno contemporâneo em rápida expansão e que, por sua extensiva abrangência, tem afetado significativamente muitos relacionamentos. Para eles, essa rede social se transformou em um "veneno" para os casais, na medida em que provoca situações de intenso ciúme, já que ali se compartilha um grande fluxo de informações íntimas sobre cada participante. $\mathrm{O}$ Facebook permite o acesso a informações que antes do boom da rede não era possível. Assim, um comentário banal sobre o perfil do parceiro, feito por um contato do sexo oposto, pode levar um participante à desconfiança e ao ciúme, fazendo com que ele passe a acompanhar de perto o perfil dos suspeitos. Muise, Christofides e Desmarais (2009) ainda salientam que muitas dessas informações produzem uma verdadeira espiral de ciúme, pois, na maioria das vezes, são aces- sadas fora de contexto, o que acaba por produzir múltiplas e desconfiadas interpretações.

Bauman (2012) aponta para o fato de que a internet e as redes sociais representam um meio utilizado pelos indivíduos da contemporaneidade para escaparem à solidão. Isso porque na rede existem sempre olhares conectados e disponíveis e, diante disso, cada vez mais, optamos por trocar a intimidade off-line pela massa de "intimidade" on-line. $\mathrm{O}$ autor ressalta que essa substituição parece ser uma tentativa de buscar relações mais rápidas e descomprometidas, que eliminem os desafios e dificuldades em que as relações cara a cara implicam. Bauman (2012) ainda alerta para um intrigante paradoxo derivado dessas relações on-line: estamos cada vez mais perto de pessoas das quais estamos distantes e cada vez mais distantes de pessoas das quais estamos perto.

Esse paradoxo apontado por Bauman (2012) parece repercutir diretamente na vivência da conjugalidade contemporânea, suscitando questões, principalmente, no que tange à comunicação entre os parceiros. Muitos casais, atualmente, lançam mão da rede para se comunicarem, inclusive, dentro da própria casa, como confirmam nossas escutas clínicas. Chamam o outro para jantar, desejam boa noite e até mesmo trocam declarações de amor por meio virtual. Porém, a maior dificuldade parece residir no fato de que, às vezes, os membros do casal estão juntos, em casa, no tempo e no espaço da exploração da intimidade, entretanto, não conversam entre si, já que estão com os olhos magnetizados pela tela, tal como no exemplo da propaganda que citamos.

Ao descrever os impasses da intimidade, Sennett (1993) brinca com um trocadilho em inglês, dizendo que para se atingir um sentimento de proximidade com o outro é preciso testar a relação, que comporta ao mesmo tempo um estar próximo - close - e um estar fechado - closed. Pensamos que o grande impasse da conjugalidade se anuncia precisamente através deste trocadilho, sugerido por Sennett, uma vez que se faz necessário equilibrar o estar perto (close), sem, no entanto, enclausurar a relação no estar fechado (closed). Talvez, a partir disso, possamos intuir que a extimidade virtual se apresenta como um forte fenômeno de nosso tempo por permitir a inversão dos termos, isto é, a extimidade pressupõe um estar distante e um estar aberto. Assim, a extimidade virtual pode ser entendida como uma tentativa de vivenciar tudo 
aquilo que se almeja nas relações íntimas, sem que os riscos e tensões estejam em cena. Distantes e abertas, as pessoas exploram a extimidade na rede com os outros de modo menos comprometedor e, caso a armadilha venha a se estabelecer, podem, simplesmente, desconectar.

\section{CONSIDERAÇÕES FINAIS}

O caminho percorrido até aqui aponta para expressivas transformações a respeito do significado da intimidade hoje e sua exposição, agora não mais restrita e protegida pelo âmbito privado, mas também publicada na vitrine da internet. Se a intimidade realmente sofre mudanças, se ela tem agora uma nova face éxtima virtual, o que isso traz como questão para a vivência da conjugalidade, já que esta pode ser considerada o ícone da relação de intimidade? Diante desta indagação, estabelecemos como foco deste estudo investigar as possíveis repercussões que a extimidade virtual está produzindo na vivência da conjugalidade contemporânea.

Primo (2013) coloca um importante questionamento para as pesquisas que visam a tratar de fenômenos da internet: como estudar tais situações, já que estas se transformam com uma velocidade ímpar, de modo que no mesmo instante em que as observamos elas já estão em mutação? Ainda hoje, o Facebook é a febre do momento, mas até quando isso dura? Qual será a nova febre? Como lidaremos como ela?

Entretanto, mesmo tendo em vista esse questionamento, acreditamos que a pergunta colocada por esse trabalho pode se manter, apesar das possíveis transformações da rede, como uma reflexão estendida. Isso porque, quando indagamos a respeito das repercussões da extimidade virtual na vivência da conjugalidade contemporânea, mais do que estabelecermos como foco de estudo a internet, estamos tratando de relações humanas que têm a rede como um fator de mediação.

Como endossamos por diversas vezes, consideramos que estamos diante de um novo fenômeno que abre uma série de questões e uma infinidade de respostas, uma vez que cada pessoa e cada casal tem um modo de articular essas novidades em suas vivências particulares. Entretanto, o que desejamos marcar é que de fato percebemos significativas transformações na relação entre intimidade e privacidade em nossos dias, modificações estas que estão nitidamente estampadas nas telas dos computadores interconectados em todos os cantos do mundo. De lá, jorra uma enxurrada de extimidades que querem ser acessadas, curtidas, comentadas e compartilhadas.

Pretendemos levar a diante esses questionamentos, acrescendo nossa discussão teórica com um possível estudo de campo, no qual gostaríamos de escutar as impressões dos casais de hoje a respeito das mudanças geradas pela rede. Acreditamos que um estudo de campo seria fundamentalmente complementar as presentes contribuições teóricas, além de permitir novas e ricas perspectivas para abordarmos o tema da extimidade virtual na conjugalidade.

Por ora, sem a pretensão de esgotar nossa questão, consideramos que diante do que foi exposto é possível afirmar que a extimidade virtual tem gerado mais desafios para os casais da contemporaneidade. Esses novos desafios são percebidos na forma como os parceiros lançam mão da rede para se comunicar e na maneira como lidam com as informações disponíveis na rede, que muitas vezes geram situações de ciúme e desconfiança. Chama atenção, sobretudo, que enquanto estão conectados e magnetizados pela tela, os parceiros têm cada vez menos tempo e espaço para se dedicarem à intimidade com o outro, que está ao seu lado. É assim que parece se construir o paradoxo da contemporaneidade: estamos cada vez mais perto de quem está distante e cada vez mais distante de quem está perto (Bauman, 2012; Tisseron, 2008). Resta saber aonde esse paradoxo vai nos levar.

\section{REFERÊNCIAS}

Ariès, P. (1981). História social da criança e da família. Rio de Janeiro: LTC.

Badinter, E. (1985). Um amor conquistado: o mito do amor materno. Rio de Janeiro: Nova Fronteira.

Bauman, Z. (2012). Isto não é um diário. Rio de Janeiro: Zahar.

Facebook. Apresentamos a Linha do tempo. Recuperado de: $\mathrm{http} / / / \mathrm{www} \cdot$ facebook.com/about/timeline?fref=ts. Acesso em: 02/02/2012.

Corbin, A. (2009). Bastidores. In M. Perrot (Ed.). História da Vida Privada: da revolução francesa à primeira guerra. (pp. 387-568). São Paulo: Companhia das Letras.

DaMatta, R. (1997). A Casa e a Rua: espaço, cidadania, mulher e morte no Brasil. Rio de Janeiro: Rocco.

Debord, G. (1997). A Sociedade do Espetáculo: comentários sobre a sociedade do espetáculo. Rio de Janeiro: Contraponto. 
Del Priore, M. (2011). Histórias íntimas: sexualidade e erotismo na história do Brasil. São Paulo: Planeta.

D’Incao, M. A. (2013). Mulher e família burguesa. Em M. Del Priore (Ed.), História das Mulheres no Brasil. (pp. 223-240). São Paulo: Contexto/UNESP.

Féres-Carneiro, T., Ziviani, C., \& Magalhães, A. S. (2011). Arranjos amorosos contemporâneos: sexualidade, fidelidade e dinheiro na vivência da conjugalidade. Em T. Féres-Carneiro (Ed.), Casal e Família: conjugalidade, parentalidade e psicoterapia. (pp. 27-42). São Paulo: Casa do Psicólogo.

Féres-Carneiro, T. (2001). Casamento contemporâneo: construção da identidade conjugal. Em T. Féres-Carneiro (Ed.), Casamento e Família: do social à clínica. (pp. 6780). Rio de Janeiro: Nau.

Féres-Carneiro, T. (1998). Casamento contemporâneo: o difícil convívio da individualidade com a conjugalidade. Psicologia: Reflexão e Crítica, 11(2), 379-394.

Ferry, L. (2008). Famílias, amo vocês: política e vida privada na era da globalização. Rio de Janeiro: Objetiva.

Giddens, A. (1993). A transformação da intimidade: sexualidade, amor e erotismo nas sociedades modernas. São Paulo: Unesp.

Goldenberg, M. (2010). Intimidade. Rio de Janeiro: Record.

Heilborn, M. L. (2004). Dois é par: genero e identidade sexual em contexto igualitário. Rio de Janeiro: Garamond.

Jablonski, B (2011). O país do casamento segundo seus futuros habitantes: pesquisando atitudes e expectativas de jovens solteiros. Em T. Féres-Carneiro (Ed.). Casal e Família: conjugalidade, parentalidade e psicoterapia. (pp. 27-42). São Paulo: Casa do Psicólogo.

Jablonski, B. (2003). Afinal, o que quer um casal? In T. Féres-Carneiro (Ed.). Família e Casal: arranjos e demandas contemporâneas. (pp. 141-168). São Paulo: Loyola.

Jablonski, B. (1998). Até que a vida nos separe: a crise do casamento contemporâneo. Rio de Janeiro: Agir.

Lacan, J. (2008). O Seminário, livro 16: de um outro ao outro. Rio de Janeiro: Zahar.

Lacan, J. (1988). O Seminário, livro 7: a ética da Psicanálise. Rio de Janeiro: Zahar.

Lasch, C. (1991). Refúgio num mundo sem coração: a família santuário ou instituição sitiados. Rio de Janeiro: Paz e Terra.

Matos-Silva, M., Abreu, R. S., \& Nicolaci-da-Costa, A. M. (2012). Como satisfazer nossas necessidades de interagir online em diferentes níveis de intimidade. Interação em Psicologia, 16(2), 217-226.

Miller, J.A. (2011). Extimidad. Buenos Aires: Paidós.
Muise, A., Christofides, E., \& Desmarais, S. (2009). More information than you ever wanted to know - Does Facebook bring out the green-eyed monster of jealousy? CyberPsychology and Behavior, 12(4), 441-444.

Perrot, M. (2011). História dos Quartos. São Paulo: Paz e Terra.

Perrot, M. (2009). Os atores. In M. Perrot (Ed.). História da Vida Privada: da Revolução Francesa à Primeira Guerra. (pp. 77-168). São Paulo: Companhia das Letras.

Prost, A. (2012). Fronteiras e espaços do privado. In A. Prost, \& G. Vincent (Eds.). História da Vida Privada: da Primeira Guerra a nossos dias. (pp. 13-136). São Paulo: Companhia das Letras.

Primo, A. (2013). Interações em Rede. Porto Alegre: Sulina.

Royo, P. (2012). Facebook é citado em 33\% dos pedidos de divórcio no Reino Unido. $O$ Globo. Recuperado de: http://oglobo.globo.com/blogs/nasredes/posts/2012/01/0 4/facebook-citado-em-33-dos-pedidos-de-divorcio-noreino-unido-424546.asp.

Sennett, R. (1993). O declínio do homem público: as tiranias da intimidade. São Paulo: Companhia das Letras.

Sibilia, P. (2010). Celebridade para todos: um antídoto contra a solidão? Ciência e Cultura, 62, 52-55.

Sibilia, P. (2008). O show do Eu: a intimidade como espetáculo. Rio de Janeiro: Nova Fronteira.

Singly, F. (2007). Sociologia da família contemporânea. Rio de Janeiro: FGV.

Tisseron, S. (2008). Virtuel, mon amour - penser, aimer, souffrir à l'ère des nouvelles technologies. Paris: Albin Michel.

Tisseron, S. (2005). Du désir d'intimité à celui d'extimité, et leur protection respective. L. Ibrahim-Lamrous, \& S. Muller (Eds.). L'intimité. (pp. 271-282) Paris: Presses Universitaire Blaise Pascal.

Turkle, S. (2011). Alone Together: why we expect more from technology and less from each other. New York: Basic Books.

Vaistman, J. (1994). Flexíveis e plurais: identidade, casamento e família em circunstâncias pós-modernas. Rio de Janeiro: Rocco.

Recebido em: 20/12/2013 Última alteração em: 30/10/2014 Aceito em: 03/02/2015 